\title{
High spectral resolution ozone absorption cross-sections - Part 1: Measurements, data analysis and comparison with previous measurements around $293 \mathrm{~K}$
}

\author{
V. Gorshelev, A. Serdyuchenko, M. Weber, W. Chehade, and J. P. Burrows \\ Institute of Environmental Physics, Bremen University, Bremen, Germany \\ Correspondence to: A. Serdyuchenko (anserd@iup.physik.uni-bremen.de) \\ Received: 12 May 2013 - Published in Atmos. Meas. Tech. Discuss.: 19 July 2013 \\ Revised: 7 January 2014 - Accepted: 17 January 2014 - Published: 24 February 2014
}

\begin{abstract}
In this paper we discuss the methodology of taking broadband relative and absolute measurements of ozone cross-sections including uncertainty budget, experimental set-ups, and methods for data analysis. We report on new ozone absorption cross-section measurements in the solar spectral region using a combination of Fourier transform and echelle spectrometers. The new cross-sections cover the spectral range $213-1100 \mathrm{~nm}$ at a spectral resolution of $0.02-$ $0.06 \mathrm{~nm}$ in the UV-visible and $0.12-0.24 \mathrm{~nm}$ in the IR at eleven temperatures from 193 to $293 \mathrm{~K}$ in steps of $10 \mathrm{~K}$. The absolute accuracy is better than three percent for most parts of the spectral region and wavelength calibration accuracy is better than $0.005 \mathrm{~nm}$.

The new room temperature cross-section data are compared in detail with previously available literature data. The temperature dependence of our cross-sections is described in a companion paper (Serdyuchenko et al., 2014).
\end{abstract}

\section{Introduction}

Ozone $\left(\mathrm{O}_{3}\right)$ is one of the most important atmospheric trace gases as it protects the biosphere from the harmful solar UV radiation and is an important greenhouse gas (United Nations Environment Programme, 2013). Global monitoring by ground-based and satellite-borne instruments plays a unique role in the determination of long-term trends, which is a prerequisite to study air quality, climate chemistry feedback and ozone recovery in response to the Montreal Protocol phasing out ozone-depleting substances (Harris et al., 1997).
Nowadays, remote sensing of ozone is done in different spectral regions (UV, visible, IR). The $\mathrm{O}_{3}$ absorption spectrum in the region 200-1100 nm consists of four absorption bands (Hartley, Huggins, Chappuis, and Wulf). Quantum mechanical dynamics calculations on potential energy surfaces explain the principal features of the $\mathrm{O}_{3}$ spectrum in the UV, visible and near infrafed (NIR) wavelength regions (Banichevich et al., 1993; Grebenshchikov et al., 2007; Schinke and McBane, 2010). The assignment of absorption bands from nine electronic states was very comprehensibly illustrated using one-dimensional cuts through the potential energy surfaces (Grebenshchikov et al., 2007). However, because of the relatively high density of low-lying states and coupling effects, the quality of the $a b$ initio calculations is still inferior to experimental data accuracy. Results of numerous experimental studies can be found, for example, in the online spectral database of gaseous molecules of the MaxPlanck Institute for Chemistry in Mainz (MPI) (Keller-Rudek and Moortgat, 2013), which contains data obtained by more than 40 teams covering different spectral regions and temperatures.

The requirement to measure small changes in stratospheric and tropospheric $\mathrm{O}_{3}$ places strong demands on the accuracy of the $\mathrm{O}_{3}$ absorption cross-sections and line parameters used in retrievals from remote sensing spectrometers. Besides, accurate measurements are very useful for the assessment of the structure, potential energy diagram, and electronic states of ozone. The following requirements can be postulated: 
- spectral resolution of the cross-sections should be at least one order of magnitude better than the instrumental bandwidths of modern remote sensing spectrometers;

- the spectral region measured needs to be sufficiently wide to include spectral channels and windows of as many instruments as possible to provide consistency between the various retrievals;

- data should be available for an adequate temperature range corresponding to that observed in the atmosphere.

Criteria for the choice of a preferred absorption crosssection dataset have been a subject of discussions within the $\mathrm{O}_{3}$-observing community. A large-scale initiative to review and recommend $\mathrm{O}_{3}$ cross-sections for all commonly used atmospheric remote sounding instruments was started in spring 2009. The ACSO (Absorption Cross Sections of Ozone) committee was established by the Scientific Advisory Group of the Global Atmosphere Watch of the World Meteorological Organization (WMO-GAW) and the International Ozone Commission of the International Association of Meteorology and Atmospheric Sciences (IO3C-IAMAS). A short summary of several published datasets that are currently used in modern remote sensing applications and are used in our comparisons here is given in the following paragraphs.

The high-resolution broadband data obtained by Bass and Paur (abbreviated as BP) (Bass and Paur, 1985; Paur and Bass, 1985) are used in the standard $\mathrm{O}_{3}$ total column and profile retrievals using ground-based and satellite spectrometers - Brewer (Komhyr and Evans, 2008), Dobson (Scarnato et al., 2009), SBUV ${ }^{1}$ (NOAA, 2007), TOMS ${ }^{2}$ (McPeters et al., 1998) and $\mathrm{OMI}^{3}$ (Veefkind and de Haan, 2002). These data are also included in the latest version of the high-resolution transmission molecular absorption database HITRAN ${ }^{4} 2008$ (Rothmann et al., 2009); however, a wavelength shift must be applied to obtain optimum results in the Huggins band. In addition, this dataset is limited to the spectral region 245$343 \mathrm{~nm}$ and the lowest temperature available is $203 \mathrm{~K}$.

The high-resolution broadband data obtained by Brion, Malicet, Daumont (abbreviated as BMD) (Brion et al., 1993, 1998; Daumont et al., 1992; Malicet et al., 1995) are available for the spectral range $195-830 \mathrm{~nm}$ at room temperature and for $194.5-520 \mathrm{~nm}$ for several lower temperatures down to $218 \mathrm{~K}$. These data are used, for example, for the most recent SBUV version 8.6 retrievals (Bhartia et al., 2013).

The high-resolution temperature-dependent broadband cross-sections obtained previously by the University of

\footnotetext{
${ }^{1}$ Solar Backscatter Ultraviolet Radiometer

${ }^{2}$ Total Ozone Mapping Spectrometer

${ }^{3}$ Ozone Monitoring Instrument

${ }^{4}$ High-resolution transmission molecular absorption database
}

Bremen team using a Fourier transform spectrometer in the range $230-830 \mathrm{~nm}$ were recorded at five temperatures (Voigt et al., 2001) using total sample pressures of 100 and 1000 mbar to inspect possible pressure effect.

The low-resolution broadband cross-sections obtained by the Bremen team using original satellite flight model (FM) spectrometers - SCIAMACHY ${ }^{5}$, GOME $^{6}$ and GOME-2 FM3 (Bogumil et al., 2003; Burrows et al., 1999a; Chehade et al., 2013a,b) - provided pre-flight information about the performance of the instruments. In addition, they are a unique source of reference spectral data otherwise not available. These datasets have the advantage that prior knowledge of instrumental slit functions is not needed if used in the ozone retrieval with the same flight model. However, transformation of these datasets for use with other instruments, having similar but different instrument functions, is not straightforward. Currently the Bogumil et al. (2003) dataset is used for retrievals of the SAGE II $^{7}$, SAGE III (McCormick et al., 1989) and OSIRIS ${ }^{8}$ (OSIRIS, 2012) spectra in addition to SCIAMACHY. Weber et al. (2011) considered the impact of absorption cross-section choice on total $\mathrm{O}_{3}$ retrieval applied to GOME, SCIAMACHY, and GOME2 and discussed the issues associated with resolution matching, wavelength shifts, and scalings. As a consequence the ozone cross-section data for GOME2 FM3 and SCIAMACHY have been adjusted as reported by Chehade et al. (2013a, b).

Measurements have been performed at single wavelengths in the absorption minimum between the Huggins and Chappuis bands and in the Wulf band by Axson et al. (2011), Anderson and Mauersberger (1992), Enami et al. (2004) and El Helou et al. (2005). These provide additional information for spectral regions where existing broadband datasets demonstrate strong disagreement or only a single broadband measurement is available.

Despite high quality, the mentioned datasets do not address the demands on the resolution, spectral coverage and availability at different temperatures, needed for modern remote sensing instruments. The dataset reported here provides broad spectral coverage from 213 to $1100 \mathrm{~nm}$ with high spectral resolution of $0.02-0.06 \mathrm{~nm}$ in the UV-visible (vis) and $0.12-0.24 \mathrm{~nm}$ in the NIR at 11 temperatures down to $193 \mathrm{~K}$.

In the Sect. 2 of this paper, we consider the experimental techniques for obtaining broadband absolute cross-sections at temperatures ranging from 193 to $293 \mathrm{~K}$. We critically discuss both uncertainties related to the current work and other datasets that are currently available.

The ozone absorption at temperature of $296 \pm 3 \mathrm{~K}$ is the most investigated case; thus a lot of high quality data are available nowadays, making a comprehensive analysis

\footnotetext{
${ }^{5}$ SCanning Imaging Absorption SpectroMeter for Atmospheric CHartographY

${ }^{6}$ Global Ozone Monitoring Experiment

${ }^{7}$ Stratospheric Aerosol and Gas Experiment

${ }^{8}$ Optical, Spectroscopic, and Infrared Remote Imaging System
} 
possible over a wide spectral region. This paper is mostly focused on the analysis of the data at room temperature. Data quality assessment is tightly bound to the feasibility of the methods for comparison of datasets characterized by different spectral resolution. In Sect. 3, we review these methods for every band in the UV-vis-NIR and provide details on our data analysis and comparisons of this work with published cross-sections at room temperature ( $293 \mathrm{~K})$. In Sect. 4, we summarize results of our measurements and analysis. In the companion paper (Serdyuchenko et al., 2014), we report on the temperature dependence of our new cross-sections and provide comparison with other data available at temperatures below $293 \mathrm{~K}$.

\section{Experimental methods and instruments}

\subsection{Experimental setup and conditions}

According to the Beer-Lambert law, a cell containing a characteristic absorbing gas with cross-section $\sigma(\lambda)$ exponentially attenuates initial light intensity $I_{0}$ at wavelength $\lambda$. Thus, the magnitude of the absorption cross-sections $\sigma$ is directly proportional to the optical density $d$, which is given by the natural logarithm of the ratio of initial light intensity to the attenuated intensity:

$\sigma(\lambda)=d \cdot k T / p L=\ln \left(I_{0} / I\right) \cdot k T / p L$,

where $p$ is the absorbing gas partial pressure, $T$ is the gas temperature, $L$ is the absorption path length and $k$ is the Boltzmann constant. The light intensity must be weak enough to avoid perturbations in the population of electronic vibrational-rotational states.

The values of the $\mathrm{O}_{3}$ cross-sections in the UV-visibleNIR cover more than seven orders of magnitude, while the dynamic range of a single measurement typically allows optical density changes of only about one order of magnitude to be measured. In this study, to achieve the required dynamic range, seven or more absorption measurements at different experimental conditions were combined for every temperature.

Experiments were carried out using two absorption cells (Fig. 1), which are cylindrical double-jacketed quartz vessels having a total length of $140 \mathrm{~cm}$ and an inner diameter of $5 \mathrm{~cm}$, sealed with evacuated quartz windows at both ends. There is a short path across the middle of one of the cells for measurements of strong absorption in the UV. In addition, this cell utilizes White-type multipass optics (White, 1942) to increase the absorption path length for measuring the weak absorption near $380 \mathrm{~nm}$. The cells were designed to achieve diverse combinations of the following parameters: $\mathrm{O}_{3}$ fraction in the mixture from zero to almost $100 \%$, total gas pressure of 50-900 mbar, and absorption lengths of 5, 135, 270, and about $2000 \mathrm{~cm}$. These combinations allows to obtain optical density of $0.1-1$ for broad spectral range from UV to NIR.
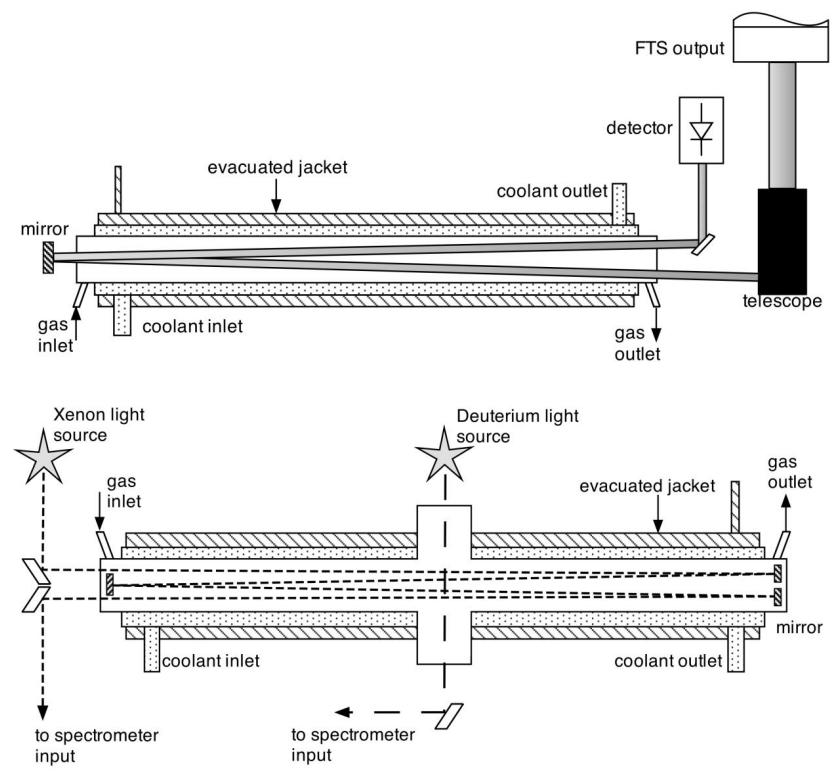

Fig. 1. Experimental setups. Upper panel: absorption cell coupled to the FTS. Lower panel: white absorption cell coupled to the echelle spectrometer. The shortest path length was achieved using the cross path.

A layer of flowing ethanol, which is insulated from the ambient air by the evacuated outer jacket, surrounds the inner volume of the cells. The outer surface of the cells is wrapped in aluminum foil and insulating foam. Stable cell temperatures from 293 down to $193 \mathrm{~K}$ were maintained by special thermostat systems (Haake CT90W Phoenix 2 cryostats). The temperature was measured using internal cryostat sensors and external Pt-100 sensors, the latter being installed inside the cells at both ends (not shown in Fig. 1).

Gas supply and vacuum systems (omitted in Fig. 1 to avoid overload of the schematic diagrams) include the rotary vane pumps connected to the cells and several instruments measuring pressure and flow rate (MKS Baratrons). The cells were pumped down to pressures below $0.01 \mathrm{mbar}$ before filling with gas. The gas pressure in the ozone generators and the whole oxygen supply system were kept above ambient pressure in order to avoid oxygen dilution in the event of leaks. Ozone-oxygen mixtures were prepared from pure oxygen, by flowing it through an ozone generator, which is in principle a coaxial cylindrical capacitor where electrical field accelerates electrons and causes the dissociation of oxygen molecules. Two types of ozone generators with efficiency up to $10 \%$ and a production rate controllable with an accuracy of about $10 \%$ provided the desired ozone concentration.

\subsubsection{Absolute calibration}

For the absolute calibration of the relative optical density spectra, we have chosen a method based on pure $\mathrm{O}_{3}$ pressure measurements as the most independent and straightforward 
technique. We performed absolute broadband measurements in spectral regions of relatively large cross-sections in the Huggins and Chappuis bands, using absorption path lengths of 135 and $270 \mathrm{~cm}$, respectively. In this case, we achieved sufficiently strong absorption with a pure $\mathrm{O}_{3}$ pressure of about 50 mbar. Pure $\mathrm{O}_{3}$ was extracted from the ozoneoxygen mixture flown through a quartz trap immersed in a Dewar with liquid nitrogen. Due to the difference of boiling temperatures, oxygen was easily pumped out from the trap while $\mathrm{O}_{3}$ was condensed on the bottom of the trap. After sufficient $\mathrm{O}_{3}$ was collected, the trap was warmed up, and evaporated $\mathrm{O}_{3}$ was fed into the evacuated cells through the Teflon tube of about $1 \mathrm{~m}$ length. During all experiments, the leak rate in the cell was below $0.04 \mathrm{mbarh}^{-1}$.

Due to the instability of ozone molecules, absolute measurements were carried out under very careful control of temperature and pressure. Ozone decay during absolute measurements can be taken into account by means of various methods. Two different spectra $\left(I_{1}, I_{2}\right)$ can be used, recorded over a short time within which $\mathrm{O}_{3}$ decay can be assumed negligible and separated by a time interval needed to obtain a measurable $\mathrm{O}_{3}$ pressure difference $p_{1}-p_{2}$ (Griggs, 1968; Molina and Molina, 1986; Yoshino, 1988):

$\sigma\left(I_{1}, I_{2}, p_{1}, p_{2}, k, T, L\right)=\ln \left(I_{2} / I_{1}\right) \cdot k T /\left(p_{1}-p_{2}\right) L$.

In this way, the absolute value of the absorption cross-section depends only on the pressure difference observed in the cell. However, only a very limited number of accumulated spectra and poor signal-to-noise ratio are possible at temperatures above $243 \mathrm{~K}$ because of rapid $\mathrm{O}_{3}$ decay. For temperatures below $243 \mathrm{~K}, \mathrm{O}_{3}$ decay slows down and a measurable pressure difference is achieved only after a fairly long time (more than four hours). Unfortunately such long measurements suffer from lamp intensity drifts. Using this method, we could only achieve an insufficient signal-to-noise ratio.

Therefore, similar to other studies (e.g. El Helou et al., 2005) the actual $\mathrm{O}_{3}$ pressure $p(t)$ in our leak-tight cell was obtained by observation of the change in the total pressure $p_{\text {total }}(t)$,i.e. the pressure change $\Delta p$ after the initial $\mathrm{O}_{3}$ pressure $p_{i}$, the latter being measured immediately after the cell was filled:

$p(t)=p_{i}-2 \Delta p=3 p_{i}-2 p_{\text {total }}(t)$.

Acquisition of background spectra, defined as having negligible $\mathrm{O}_{3}$ absorption, and absorption spectra of $\mathrm{O}_{3}\left(I_{0}\right.$ and $I$, respectively) were separated by the time needed (i) to fill the evacuated cell with ozone, typically about a minute, and (ii) to accumulate spectra for sufficient signal-to-noise ratio, typically over an hour. To control lamp intensity drifts, two background spectra were measured: before filling the cell with ozone and after evacuating the cell. Background spectra were averaged from over about 800 spectral scans, $\mathrm{O}_{3}$ spectra were recorded in 50 separate files, with each file being an average of 20 scans collected during several minutes.
Every file was assigned to the actual $\mathrm{O}_{3}$ pressure $p(t)$ in the cell, whereby $\mathrm{O}_{3}$ decay on a timescale of several minutes was taken into account:

$\sigma\left(t, I, I_{0}, p, k, T, L\right)=\ln \left[I_{0} / I(t)\right] \cdot k T / p(t) L$.

This method yields low-noise spectra since absorption spectra at a particular pressure are referenced to the stable background spectrum and results are averaged. Unfortunately, the method does not control for any ozone decay prior to start of the measurements. Overestimation of the $\mathrm{O}_{3}$ concentration would lead to an underestimation of cross-sections. Ozone pressure $p_{i}$ at the beginning of the measurements was corrected for the amount decayed during filling the cell. Correction was done by means of extrapolation of long time (an hour or more) observations of the total pressure changes in the cell. Depending on the gas temperature in the cell, it was up to several percent. Based on numerous repeated measurements and the quality of extrapolation, we estimated an uncertainty of about $1 \%$ in the knowledge of the initial ozone purity at room temperature.

\subsubsection{Relative measurements}

Some $\mathrm{O}_{3}$ absorption at $255 \mathrm{~nm}$ was observed after the cell was evacuated, which is probably due to an $\mathrm{O}_{3}$ layer of unknown depth remaining attached to the optical surfaces. This effect could not be neglected during measurements in the Hartley band performed using the short path; therefore, in this spectral region the relative cross-sections were measured using oxygen-ozone mixture.

Oxygen-ozone mixtures were also used for weak $\mathrm{O}_{3}$ absorption measurements in the minimum between Huggins and Chappuis bands and in the Wulf band to avoid risk of explosions. We concatenated the absolute and relative spectra obtained from series of experiments using different combinations of cell lengths and gas mixtures (pure ozone and oxygen-ozone mixtures) as listed in Table 1. Relative crosssections were concatenated with the absolute ones using scaling and offset coefficients, introduced to compensate for small drifts of the lamp intensity. Only those parts of the spectra with optical density between 0.1 and 2 were taken for concatenation in order to obtain the best possible signalto-noise ratio and to avoid saturation. Optical densities as low as 0.01 were only used at the $\mathrm{O}_{3}$ absorption minimum around $380 \mathrm{~nm}$ and in the NIR region.

\subsection{Spectrometers}

Echelle spectrometer (ESA 4000, LLA Berlin) and a Bruker HR120 Fourier transform spectrometer (FTS) provided high spectral resolution, high wavelength accuracy and adequate signal-to-noise ratio over the entire optical spectral range. The spectral resolution of both spectrometers was significantly and sufficiently higher than that of the spectral features 
Table 1. Experimental setups for different spectral regions.

\begin{tabular}{lllllll}
\hline $\begin{array}{l}\text { Spectral } \\
\text { region, nm }\end{array}$ & $\begin{array}{l}\text { Spectrometer, } \\
\text { detector }\end{array}$ & Resolution & Calibration & $\begin{array}{l}\text { Absorp. } \\
\text { path, cm }\end{array}$ & $\begin{array}{l}\text { Lamp drift, } \\
\%^{*}\end{array}$ & $\begin{array}{l}\text { Optical } \\
\text { density }\end{array}$ \\
\hline $213-310$ & echelle, ICCD & $0.018 \mathrm{~nm}$ & Relative & 5 & De, 0.5 & $0.5-2$ \\
$310-335$ & FTS, GaP & $1 \mathrm{~cm}^{-1}$ & Absolute & 135 & Xe, 2 & $0.1-2$ \\
$335-350$ & FTS, GaP & $1 \mathrm{~cm}^{-1}$ & Relative & 270 & Xe, 1 & $0.1-1$ \\
$350-450$ & echelle, ICCD & $0.02 \mathrm{~nm}$ & Relative & $\sim 2000$ & Xe, 1 & $0.05-1$ \\
$450-780$ & FTS, Si & $1 \mathrm{~cm}^{-1}$ & Absolute & 270 & Tungsten, 0.2 & $0.05-2$ \\
$780-1100$ & FTS, Si & $2 \mathrm{~cm}^{-1}$ & Relative & 270 & Tungsten, 0.2 & $0.001-0.1$ \\
\hline
\end{tabular}

* During typical measurement time.

observed. As a result, smooth spectral matching between spectra from both spectrometers was possible.

Measurements involved three different light sources: deuterium and xenon super quiet gas discharge lamps in the UV shorter than $300 \mathrm{~nm}$ and $300-450 \mathrm{~nm}$, respectively, and tungsten filament lamp in the visible and NIR from $450 \mathrm{~nm}$ to $1100 \mathrm{~nm}$. The echelle spectrometer is equipped with an intensified charge-coupled device (ICCD) matrix detector $(1024 \times 1024$ pixel), having high sensitivity in the UV region. The FTS was used with semiconductor detectors for measurements in the visible and infrared spectral regions. More information on the FTS setup can be found in Voigt et al. (2001).

Both spectrometers yield wavelength calibrations with an accuracy of $0.005 \mathrm{~nm}$ in the UV and visible. The echelle spectrometer has a changing linear dispersion per pixel $(24 \mu \mathrm{m})$ as a function of wavelength being $0.005,0.010$ and $0.019 \mathrm{~nm}$ at 200, 400 and $780 \mathrm{~nm}$, respectively. The resolving power $\lambda / \Delta \lambda$ is 40000 with respect to one pixel. Measurements of the Hg-Cd lamp spectrum were used to determine resolution, i.e. the full-width half-maximum (FWHM), from about $0.015 \mathrm{~nm}$ in the UV to $0.025 \mathrm{~nm}$ in the visible. The echelle spectrometer delivers data on air wavelength scale, which was converted into vacuum wavelength scale using Edlen's equation (Edlen, 1966). FT spectra were recorded at constant spectral resolution of $1 \mathrm{~cm}^{-1}$ in the UV and the visible, and $2 \mathrm{~cm}^{-1}$ in NIR spectral ranges (optical path difference 0.9 and 0.45 , respectively) with a boxcar apodization. Wave number scale delivered by FTS was converted into the vacuum wavelength scale. The spectral resolution of the FTS is about $0.01 \mathrm{~nm}$ in the Huggins band, $0.02-0.06 \mathrm{~nm}$ in the Chappuis band, and $0.12-0.24 \mathrm{~nm}$ in the Wulf band.

The sampling rate is $0.01 \mathrm{~nm}$ for the echelle spectrometer. The sampling of the FT spectrometer changes from $0.005 \mathrm{~nm}_{\text {point }}{ }^{-1}$ in the near UV to $0.01-0.03 \mathrm{~nm} /$ point in the visible and about $0.1 \mathrm{~nm}$ point $^{-1}$ in the NIR. For convenience, the cross-sections were linearly interpolated onto an equidistant wavelength grid in steps of $0.01 \mathrm{~nm}$ for the spectral range from 213 to $1100 \mathrm{~nm}$. The interpolation procedure for the experimental FTS data results in one to three

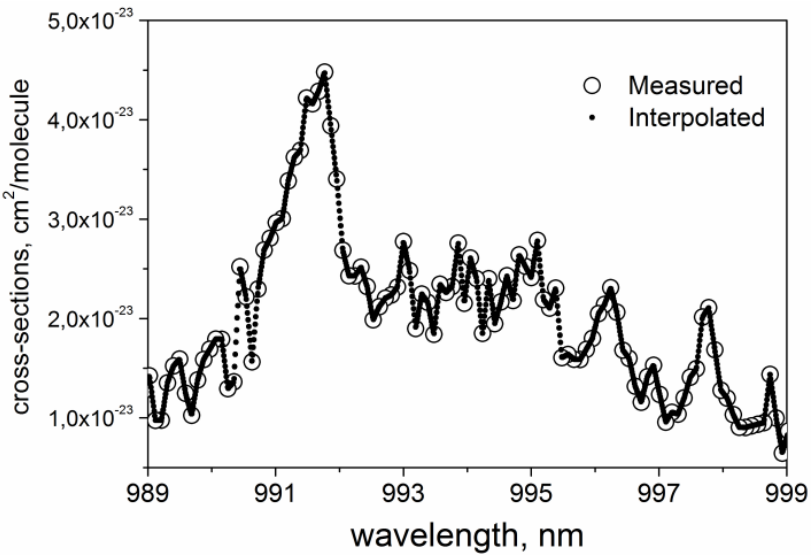

Fig. 2. Final steps in spectra processing: interpolation of the experimental spectra in near-infrared spectral region.

calculated points placed between the measured points in the $450-750 \mathrm{~nm}$ region and up to nine additional points in the NIR (Fig. 2).

\subsection{Uncertainty budget}

The assessment of the uncertainty budget for absorption cross-sections is a complex task. The total uncertainty of absolute measurements consists of uncertainties of the optical density and absolute scaling parameters: temperature, ozone pressure and cell length.

\subsubsection{This work}

The length of the absorption cell (more than $1 \mathrm{~m}$ ) made it possible to measure the absorption path with high accuracy using a ruler. Thickness of windows was taken into account using a caliper. The uncertainties in the temperature and pressure measurements contribute both to statistical and systematic uncertainties of cross-sections. The largest uncertainty in the absolute calibration is due to the ozone pressure, corrected for decay as discussed earlier. Fluctuations of pressure during measurements were below the sensitivity of the 
digital readout of the pressure sensors ( 0.04 mbar). Accuracy of a calibrated pressure sensor is $0.5 \%$ of the reading value (according to manufacturer specifications). The thermostats maintain a given temperature with a stability of $\pm 0.3 \mathrm{~K}$ or better. Calibrations of the internal sensors of the thermostats were checked using several alcohol thermometers; possible offsets were found to be less than $1 \mathrm{~K}$. Readings of the external Pt sensors installed on both ends of the cells and the internal thermostat sensors agreed to within $1 \mathrm{~K}$ or better, confirming the uniformity of the temperature in our setups.

The statistical uncertainty in optical density arises from the ozone temperature and pressure fluctuations described above and the fluctuation of the light source intensity. The latter is a result of a tradeoff between white noise reduction (lower for long integration) and lamp intensity drift during accumulation and averaging of spectra (lower for short integration). This uncertainty is determined after averaging subsequent baseline spectra, recorded without ozone. Obtained standard deviation must be multiplied by the square root of 2 , because this uncertainty contributes both to the baseline and to absorption measurements ( $I_{0}$ and $I$ ). Proper choice of the experiment duration results in uncertainty of the baseline at the level of $0.5 \%$ and better, in best cases down to $0.1 \%$.

Performance of the optical system (lamps spectra, detector sensitivity curves, etc.) and shape of the absorption spectra lead to a complicated wavelength dependence of the relative uncertainty of the optical density. At identical signal-tonoise ratio, it can change by at least one order of magnitude within a single measurement in parts of the spectrum exhibiting steep slopes, particularly in the Huggins or Wulf bands. Optical densities measured at different spectral regions are given in Table 1 together with lamp stabilities. For simple estimation, we use the statistical uncertainty related to the source stability at optical density of unity. This is valid for almost the entire Hartley and Huggins bands and the 450$750 \mathrm{~nm}$ region; however, it strongly underestimates the error bars in the spectral regions with weak absorption between Huggins and Chappuis bands and in the NIR Wulf band. One should keep in mind that quality of the system performance and signal-to-noise ratio typically fall towards edges of the measured spectra.

Table 2 summarizes the upper estimations for uncertainties from different sources for the $\mathrm{O}_{3}$ cross-sections absolutely measured in the Huggins band and Chappuis band. The systematic uncertainty is about $1 \%$; the statistical uncertainty at optical density of unity is $1-3 \%$ in UV and in the visible. In the spectral regions characterized by weak absorption, statistical uncertainty can reach up to $20 \%$ or more due to the very low optical density (Table 1). The systematic uncertainty of the absolute measurements propagates into the relative measurements. For relative measurements, additional uncertainties arise from the scaling of these spectra to the absolute calibrated spectra. However, these uncertainties are negligible because differences between the matched spectra are typically much smaller than the estimated experimental uncertainty.

\subsubsection{Previous studies}

Since information on the total uncertainty is particularly important when comparing different datasets, we shall briefly discuss uncertainties of some published broadband data.

Bass and Paur report $1 \%$ noise during their measurements (Bass and Paur, 1985; Paur and Bass, 1985). This random uncertainty needs to be added to the systematic uncertainty arising from their absolute calibration. The data were absolutely calibrated for all temperatures using Hearn's value at the $\mathrm{Hg}$ lamp line at $253.65 \mathrm{~nm}$, which is $1147 \times 10^{-20} \mathrm{~cm}^{2}$ molecule ${ }^{-1}$ (Hearn, 1961). Hearn himself states best estimates of the cross-section at $253.65 \mathrm{~nm}$ as $(1147 \pm 24) \times 10^{-20} \mathrm{~cm}^{2} \mathrm{molecule}^{-1}$, i.e. $2.1 \%$. Therefore, the total uncertainty of BP data exceeds $2 \%$. At other wavelengths of $\mathrm{Hg}$ lamp lines in the Hartley band, BP data agree with Hearn's data within 2-3\%.

A systematic uncertainty of at least $2 \%$ in the SCIAMACHY dataset by Bogumil et al. (2003) arises because BP data have been used for absolute calibration. Bogumil et al. estimated a total uncertainty of about $3 \%$ or better, excluding regions with cross-sections below $10^{-23} \mathrm{~cm}^{2}$ molecule ${ }^{-1}$ $(365-410 \mathrm{~nm}$ and longer than $950 \mathrm{~nm})$ and the $305-320 \mathrm{~nm}$ spectral region (spectral channel edges). This total uncertainty includes an uncertainty arising from the scaling procedure during concatenation. The Bogumil et al. (2003) dataset was obtained using concatenation of several spectra performed from UV to NIR covering a broad region from 230 to $1075 \mathrm{~nm}$. Consecutive concatenations starting from the Hartley band towards longer wavelengths can lead to an accumulated uncertainty towards the Chappuis and Wulf bands, because BP data are only available in the Hartley-Huggins bands.

The other satellite dataset - GOME flight model data - was absolutely calibrated using the titration method (Burrows et al., 1999a). The accuracy stated is $2.6 \%$, with less than $2 \%$ assigned to the lamp intensity drift. Integrated absorption cross-sections recorded with the GOME-FM instrument were used for the absolute calibration of the FTS dataset by Voigt et al. (2001). The spectral wavelength accuracy of the Voigt et al. (2001) data is better than $0.5 \mathrm{pm}$ at $230 \mathrm{~nm}$ and $7.2 \mathrm{pm}$ at $850 \mathrm{~nm}$.

The BMD team states a total systematic uncertainty of $1.5 \%$ in the spectral region $420-830 \mathrm{~nm}$ and $1.5-4 \%$ at $350-$ $420 \mathrm{~nm}$ and a statistical uncertainty (root mean square) of 0.9-2\% (Brion et al., 1998). In the earlier works in the UV region the BMD team states a total systematic uncertainty of $1.3 \%$ in the Hartley band and $1.3-2.5 \%$ in the Huggins band and a statistical uncertainty of $0.9-2.2 \%$ (Daumont et al., 1992).

We conclude that uncertainty of our dataset $(2-3 \%$ for most of the spectral regions) is comparable to other 
Table 2. Uncertainty in the absorption cross-section obtained from absolute measurements at 50 mbar and $293 \mathrm{~K}$ and path lengths of 135 and $270 \mathrm{~cm}$ in the Huggins band and Chappuis band, respectively. Upper estimations are given.

\begin{tabular}{ll}
\hline Systematic uncertainty & Statistical uncertainty \\
\hline Gas supply system purity: & Ozone impurity due to decay: $1 \%$ \\
- oxygen impurity: $0.005 \%$ & Pressure fluctuations: $0.08 \%(0.04 \mathrm{mb})$ \\
- leaks: $0.1 \%$ & Temperature fluctuations: $0.1 \%(0.3 \mathrm{~K})$ \\
Pressure sensor uncertainty: $0.5 \%(0.25 \mathrm{mb})$ & Light source stability ${ }^{\mathrm{a}, \mathrm{b}}: 0.28-2.8 \%$ \\
Temperature sensor uncertainty: $0.3 \%(1 \mathrm{~K})$ & \\
Temperature non-uniformity: $0.3 \%(1 \mathrm{~K})$ & \\
Cell length $: 0.04,0.07 \%(1 \mathrm{~mm})$ & \\
Total: $1.3 \%$ & Total $(\mathrm{RMS})^{\mathrm{b}}: 1-3 \%$ \\
\hline
\end{tabular}

${ }^{\mathrm{a}}$ Relative to optical density $\mathrm{OD}=1 .{ }^{\mathrm{b}}$ Depending on spectral region; see Table 1.

broadband data measured so far. In ozone retrievals from remote sensing, an additional uncertainty may arise from data convolution with the instrumental slit functions and, therefore, depends on the accurate knowledge of those.

\section{Results and analysis}

The new room-temperature ozone absorption cross-sections in the entire measured region are shown in Fig. 3 together with the high-resolution BMD dataset (Brion et al., 1998) and lower-resolution satellite spectrometer datasets obtained by Burrows et al. (1999a) and Bogumil et al. (2003). Figure 3 also contains cross-section values at single wavelengths obtained by El Helou et al. (2005), Axson et al. (2011), and Anderson et al. (1993).

The spectral window at $325-335 \mathrm{~nm}$ is used in retrieval algorithms based on the differential optical absorption spectroscopy (DOAS) in the Huggins band (Weber et al., 2011). The vertical lines schematically mark the single wavelengths used in retrieval algorithms of the spectra obtained by different ground-based and remote sensing instruments for detection of $\mathrm{O}_{3}$, trace gases, clouds and aerosols (SBUV, OMI, TOMS, OSIRIS, SAGE, Brewer, Dobson). Despite the fact that most channels are present in the UV spectral region, there are important channels in the visible and IR as well.

Review by Orphal (2003) provided analysis on broadband data obtained before 2003. Following a similar approach, we analysed the new absorption cross-sections at the temperature of $293 \mathrm{~K}$ :

- scaling factors between our new data and selected published band-integrated cross-sections are determined;

- a comparison between our results with the published datasets at wavelengths of the He-Ne laser, $\mathrm{Hg}$ lamp, and spectral channels of various remote sensing instruments is made;

- scaling factors and wavelength shifts are determined with respect to the high spectral resolution datasets

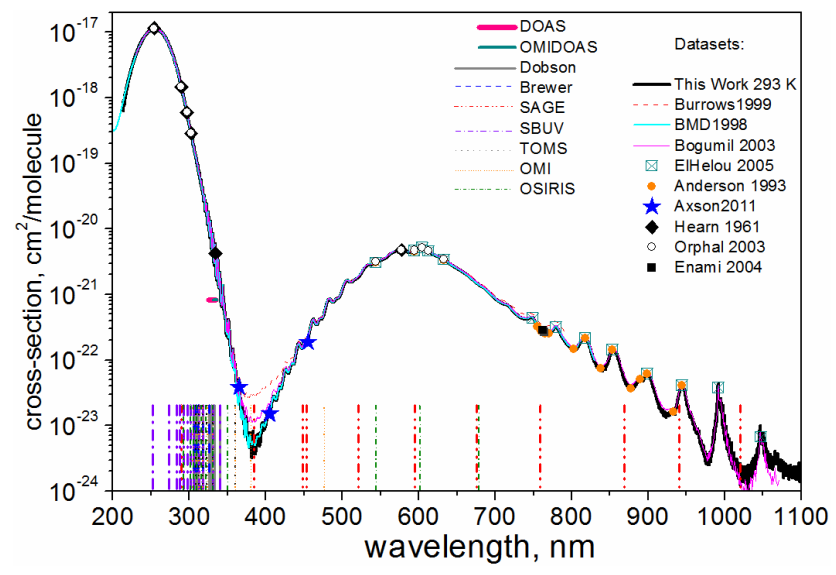

Fig. 3. Ozone absorption cross-section at room temperature. Notations for datasets: black solid line - this work; magenta solid line Bogumil et al. (2003); light blue solid line - BMD; dash line - Burrows et al. (1999a). Symbols: cross - El Helou et al. (2005); closed circle - Anderson et al. (1993); star - Axson et al. (2011); open circle - Orphal (2003); diamond - Hearn (1961); closed square Enami et al. (2004). Notations for instrument channels: solid horizontal lines - DOAS and OMI-DOAS in Huggins band. Vertical lines: grey solid - Dobson; dash - Brewer; dash-dot-dot - SAGE; dash-dot - SBUV; dots - TOMS; short dots - OMI; short dash-dots - OSIRIS.

(BMD and BP) and the lower spectral resolution datasets (GOME, GOME-2, SCIAMACHY) in the Hartley, Huggins, and Chappuis bands.

\subsection{Band-integrated cross-sections}

The integrated absorption cross-sections over an electronic band are only dependent on the number of molecules in the lower state and the transition probability (Burrows et al., 1999a). Absorption cross-section of ozone rapidly decreases away from the band maximum; therefore integrated band intensity is weighted to the largest values of the absorption cross-sections. Consequently, the comparisons of integrated 
cross-sections reflect mainly the knowledge of the crosssections close to the maximum of the bands. In addition, the spectral bands overlap (e.g. the high-energy tail of the Huggins band continuously goes over into the Hartley band system). Nevertheless, the method is a valuable test of agreement between broadband absorption cross-section datasets having different spectral resolution.

Orphal (2003) proposed integration limits which were found from pragmatic considerations such as the quality of the considered datasets rather than the real band borders, determined by theoretical studies (Grebenshchikov et al., 2007; Banichevich et al., 1993). For comparison purposes, in this work we used the same limits. In the Wulf band, we calculated integrated absorption cross-sections for our new data and Bogumil et al. (2003) data using the range 663-1000 nm (Banichevich et al., 1993).

Table 3 presents the integrated absorption cross-sections obtained from this work, the high spectral resolution BMD dataset, the different satellite instrument datasets and the mean values obtained by Orphal from averaging several data sources (Bass and Paur, 1985; Brion et al., 1998; Voigt et al., 2001; Bogumil et al., 2003; Burrows et al., 1999a). The uncertainty of this mean value is the standard deviation from averaging. Our reported absorption cross-sections agree with all datasets within $1 \%$ in the Hartley and Huggins bands, and within $1-4 \%$ and $6 \%$ in the Chappuis and Wulf bands. Agreement with the high-resolution BMD dataset is about $1 \%$ and better.

\subsection{Hartley and Huggins bands}

The Hartley and Huggins bands (Fig. 4) are especially important for remote sensing of the atmosphere since they contain spectral channels used by both satellites and ground-based spectrometers; several satellite spectrometers work with the entire Huggins band.

\subsubsection{Spectral region near $255 \mathrm{~nm}$}

Several datasets in the region around $255 \mathrm{~nm}$ are shown in Fig. 4a. The uncertainty reported by Hearn is about $2 \%$. In general, our new absorption cross-sections are lower by several percent compared to satellites and BP datasets. Agreement with the BMD dataset is within $1 \%$. In Table 4, our new data are compared to some published data and the mean values by Orphal (2003) at selected wavelengths, corresponding to $\mathrm{Hg}$ lamp and $\mathrm{He}-\mathrm{Ne}$ lines. Some of the data were interpolated. As mentioned above, the uncertainty of the Orphal's mean data is the standard deviation from averaging over several data sources, each having its own accuracy. Near $300 \mathrm{~nm}$ our new data agree with most of the other datasets within 1-3\%. This is a region of overlap between spectra obtained using echelle and FT spectrometers in this study. Recently, Petersen et al. (2012) measured cross-sections at three wavelengths using an argon-ion laser with an experimental

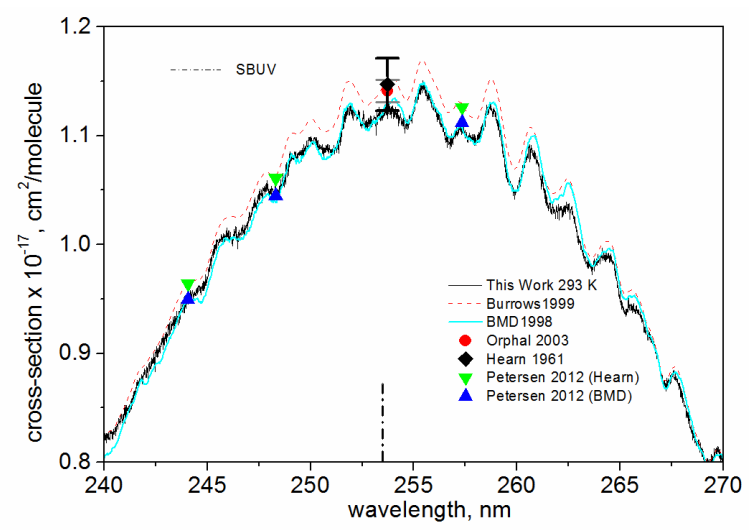

(a)

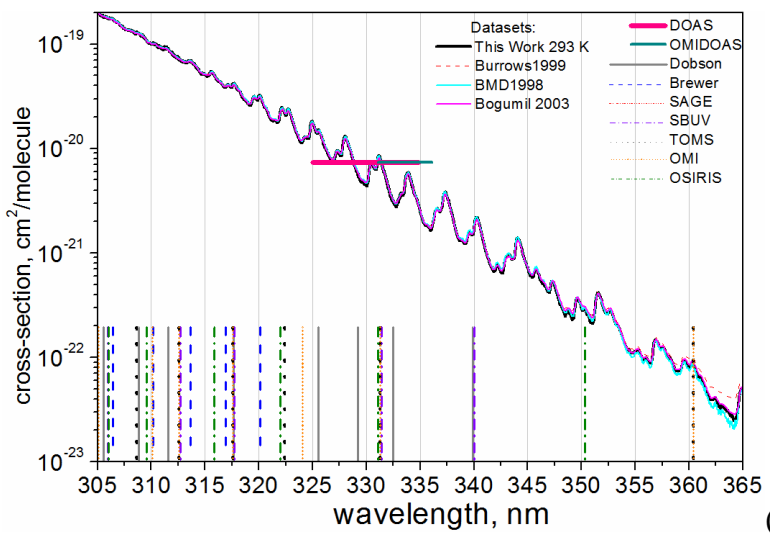

(b)

Fig. 4. Ozone absorption cross-section at room temperature in (a) Hartley band and (b) Huggins band. Notations for datasets and spectral channels are the same as in Fig. 3. Triangles are data from Petersen et al. (2012).

combined relative uncertainty of $0.085 \%$. For absolute scaling, values at $253.65 \mathrm{~nm}$ obtained by BMD and Hearn were used, which, in fact, limit the total accuracy to about $1.5-2 \%$. Agreement between our absorption cross-sections and those by Petersen et al. (2012) obtained by scaling with BMD and Hearn values is within 1 and $2 \%$, respectively.

\subsubsection{Spectral region $323-340 \mathrm{~nm}$}

The spectral region of $325-335 \mathrm{~nm}$ was selected for remote sensing retrievals as suitable to derive the total $\mathrm{O}_{3}$ column using DOAS or a modified DOAS approach (Burrows et al., 1999b). Standard DOAS derives the $\mathrm{O}_{3}$ column by fitting the slant column absorption using a reference absorption crosssection at the instrument's spectral resolution to the measured Sun-normalized radiance. The DOAS approach has been successfully applied to SCIAMACHY, GOME-2, and OMI data as well (Bovensmann et al., 1999; Veefkind and de Haan, 2002).

Dataset comparison in this region of the Huggins band is complicated due to sharp structures, which are very sensitive 
Table 3. Integrated cross-sections at room temperature (293-298 K), $\mathrm{cm}^{2}$ molecule ${ }^{-1} \mathrm{~nm}$.

\begin{tabular}{lllrrrr}
\hline Band & limits, nm & $\begin{array}{l}\text { Orphal } \\
(2003)\end{array}$ & $\begin{array}{r}\text { This } \\
\text { work }\end{array}$ & $\begin{array}{r}\text { Brion et } \\
\text { al. (1998) }\end{array}$ & $\begin{array}{r}\text { Burrows et } \\
\text { al. (1999a) }\end{array}$ & $\begin{array}{r}\text { Bogumil et } \\
\text { al. (2003) }\end{array}$ \\
\hline Hartley, $\times 10^{-16}$ & $245-340$ & $3.55 \pm 0.6 \%$ & 3.53 & 3.52 & 3.57 & 3.56 \\
Huggins, $\times 10^{-20}$ & $325-340$ & $8.30 \pm 0.7 \%$ & 8.29 & 8.30 & 8.33 & 8.31 \\
Chappuis, $\times 10^{-19}$ & $410-690$ & $6.38 \pm 1.6 \%$ & 6.22 & 6.29 & 6.45 & 6.40 \\
Wulf, $\times 10^{-19}$ & $633-1000$ & - & 1.04 & - & - & 1.10 \\
\hline
\end{tabular}

Table 4. Absolute absorption cross-sections in the UV at $295 \pm 3 \mathrm{~K}, \mathrm{~cm}^{2}$ molecule ${ }^{-1} \times 10^{-20}$.

\begin{tabular}{rrrrrrrr}
\hline Wavelength, nm & $\begin{array}{r}\text { Orphal } \\
\text { vacuum (air) }\end{array}$ & $\begin{array}{r}\text { This } \\
\text { work }\end{array}$ & $\begin{array}{r}\text { Hearn } \\
(1961)\end{array}$ & $\begin{array}{r}\text { BMD } \\
(1998)\end{array}$ & $\begin{array}{r}\text { Burrows et } \\
\text { al. (1999a) }\end{array}$ & $\begin{array}{r}\text { Bogumil et } \\
\text { al. (2003) }\end{array}$ & $\begin{array}{r}\text { Petersen et } \\
\text { al. (2012) using } \\
\text { Hearn/BMD value }\end{array}$ \\
\hline 244.06 & - & 946 & - & 949 & 964 & 965 & $964 / 950$ \\
248.32 & - & 105.1 & - & 103.8 & 106.3 & 106.3 & $106.1 / 104.5$ \\
$253.73(253.65)$ & $1141 \pm 0.9 \%$ & 1120 & 1147 & 1131 & 1150 & 1147 & - \\
257.34 & - & 1107 & - & 1107 & 1129 & 1126 & $1126 / 1112$ \\
$289.44(289.36)$ & $149 \pm 2.0 \%$ & 151 & 147 & 151 & 151.6 & 150 & - \\
$296.82(296.73)$ & $60.3 \pm 1.6 \%$ & 61.1 & 59.71 & 61.5 & 61.4 & 60.9 & - \\
e 302.24 (302.15) & $29.2 \pm 1.8 \%$ & 29.6 & 28.60 & 29.8 & 29.9 & 29.5 & - \\
\hline
\end{tabular}

to the spectral resolution of the dataset. For analysis of the scaling factors and wavelength shifts in the $323-343 \mathrm{~nm}$ region, Orphal (2003) compared different broadband databases convolved assuming a Gaussian profile with a $0.4 \mathrm{~nm}$ FWHM used a non-linear least squares fitting program.

Orphal (2003) found that the BP data show systematic wavelength differences compared to the FTS data of Voigt et al. (2001) and need to be shifted to longer wavelengths $(+0.029 \mathrm{~nm})$ with a scaling factor of 0.956 . Orphal also reports systematic wavelength differences between BMD and other datasets. He found a jump in the BMD wavelength calibration around $331 \mathrm{~nm}$, making it difficult to determine a single wavelength shift coefficient in the $323-343 \mathrm{~nm}$ region. Assuming a linear shift, Orphal reports that BMD is shifted towards shorter wavelengths $(-0.014 \mathrm{~nm})$ compared to the Voigt et al. (2001) data.

We compared our data with the published datasets, following a similar approach. One should take into account that nowadays several slightly different versions of the datasets have become available. Below are a short reference and notations used in our study. The MPI online database (Keller-Rudek and Moortgat, 2013) contains experimental BP and BMD datasets for different temperatures at air wavelengths $\left(\mathrm{BP}_{\exp }\right.$ and $\left.\mathrm{BMD}_{\exp }\right)$ obtained by personal communication in 2000 and in 1998, respectively. The same experimental BMD data can be found on the ACSO website (http://igaco-o3.fmi.fi/ACSO/cross_sections. html). The ACSO website also provides polynomial coefficients (quadratic fits) $\mathrm{BP}_{\text {calc }}$ that have been calculated by Bass and Paur for the temperature dependence of the original data excluding the $218 \mathrm{~K}$ at air wavelengths (Bass and Paur, 1985). HITRAN 2008 also contains polynomial coefficients (BP HITRAN $_{\text {) }}$; however, a few corrections were made on the original BP data: air-vacuum wavelength conversion according to Edlen's equation (Edlen, 1966) and wavelength shift. Using original BMD data at four temperatures (218, 228 , 243, and $295 \mathrm{~K}$ ), Liu et al. (2007) derived polynomial coefficients for temperature dependence for vacuum wavelength scale $\left(\mathrm{BMD}_{\text {calc }}\right)$, making possible the interpolation/extrapolation of the cross-sections to any given temperature. More details on the polynomial temperature parameterization of the cross-sections can be found, for example, in Paur and Bass (1985), Orphal (2003) and in our companion paper: Serdyuchenko et al. (2014).

For comparison we used versions of the BP and BMD datasets from the sources mentioned above as well as Voigt et al. (2001) and Bogumil et al. (2003) datasets from the website of the molecular spectroscopy group of the Institute of Environmental Physics in Bremen, Germany. To avoid altering the original data, when possible, we performed comparisons with high-resolution BP, BMD and Voigt et al. (2001) datasets without resolution matching. For the comparison with Bogumil et al. (2003) dataset, the new high-resolution dataset was convolved with the Gaussian profile with FWHM of $0.2 \mathrm{~nm}$. All datasets were compared on the same grid of vacuum wavelengths in steps of $0.01 \mathrm{~nm}$ using Edlen's equation and interpolation.

The relative difference $\delta \sigma$ between datasets $\sigma_{1}$ and $\sigma_{2}$ was calculated in percent as a function of a scaling factor $F$ and a linear wavelength shift $\delta \lambda$ : 
$\delta \sigma(\lambda)=\left[\sigma_{1}(\lambda)-F \cdot \sigma_{2}(\lambda+\delta \lambda)\right] /\left[F \cdot \sigma_{2}(\lambda+\delta \lambda)\right] \cdot 100 \%$.

We performed the analysis of the shifts and scalings for three different spectral regions: $323-330 \mathrm{~nm}, 332-340 \mathrm{~nm}$ and $323-340 \mathrm{~nm}$. For every spectral region, we calculated the mean over the region differences $\Delta \sigma$ between different pairs of datasets and found the optimum shifts and scaling factors by minimization of these mean differences. In comparisons with our new data, shifts and scaling were applied to the published datasets.

Comparison of the original experimental datasets may be controversial because "minima" in absorption features are sensitive to temperature. Even a relatively small difference of $\pm 5 \mathrm{~K}$ influences the absolute values. Our absorption crosssections and those of Voigt et al. (2001) and Bogumil et al. (2003) were obtained at $293 \mathrm{~K}$, whereas those of $\mathrm{BP}_{\exp }$ and $\mathrm{BMD}_{\text {exp }}$ were made at 298 and $295 \mathrm{~K}$, respectively. Approximation of the absorption cross-sections by fitting a second-order polynomial seems to be a reasonable solution: calculated for 298 and $295 \mathrm{~K}, \mathrm{BP}_{\text {calc }}$ and $\mathrm{BMD}_{\text {calc }}$ reproduce corresponding experimental $\mathrm{BP}_{\exp }$ and $\mathrm{BMD}_{\exp }$ data very well; mean differences are $0.3 \%$ for $\mathrm{BP}$ and $0.04 \%$ for BMD, and scaling factors are 0.998 for $\mathrm{BP}$ and 1 for BMD. Using polynomial coefficients to describe the temperature dependence reduces differences between the datasets, also due to their smoothing effect.

To test efficiency of our technique, we reproduced some results of the analysis done by Orphal (2003). We obtained similar scaling $(0.96)$ and shift $(+0.03 \pm 0.005 \mathrm{~nm})$ between $\mathrm{BP}_{\text {exp }}$ and Voigt et al. (2001) data. We found that matching $\mathrm{BP}_{\text {calc }}$ calculated for $293 \mathrm{~K}$ to the Voigt et al. (2001) dataset requires nearly negligible scaling $(0.998)$, but requires a shift of $+0.027 \pm 0.004 \mathrm{~nm}$. Our approach is also capable of revealing the shift of $+0.015 \pm 0.0005 \mathrm{~nm}$ applied to the experimental BP dataset in the HITRAN 2008 version.

Mean relative differences, shifts, and scaling factors, which match the published datasets to the new data, are shown in Fig. 5a. The uncertainties were obtained from averaging of the shifts over the regions $323-330$ and 332$340 \mathrm{~nm}$. The relative differences between our absorption cross-sections and other relevant datasets are shown in Fig. 5b. Our absorption cross-sections are slightly lower than all other datasets, but this difference is within the experimental error bars for most of the cases. Among experimental data, our new absorption cross-sections agree best with the Voigt et al. (2001) and Bogumil et al. (2003) datasets (Fig. 5a): scaling factors are 0.99 and 0.995 and mean difference is about $1 \%$. We observe a small wavelength shift of $0.005 \pm 0.002 \mathrm{~nm}$ between Voigt et al. (2001) and the new data, which exceeds the reported accuracy of the spectral calibration of the FTS $(0.002 \mathrm{~nm})$. Both measurements were performed under similar conditions using the same instrument in the Bremen laboratory; however, the spectral resolution of the Voigt et al. (2001) data is $5 \mathrm{~cm}^{-1}$, whereas

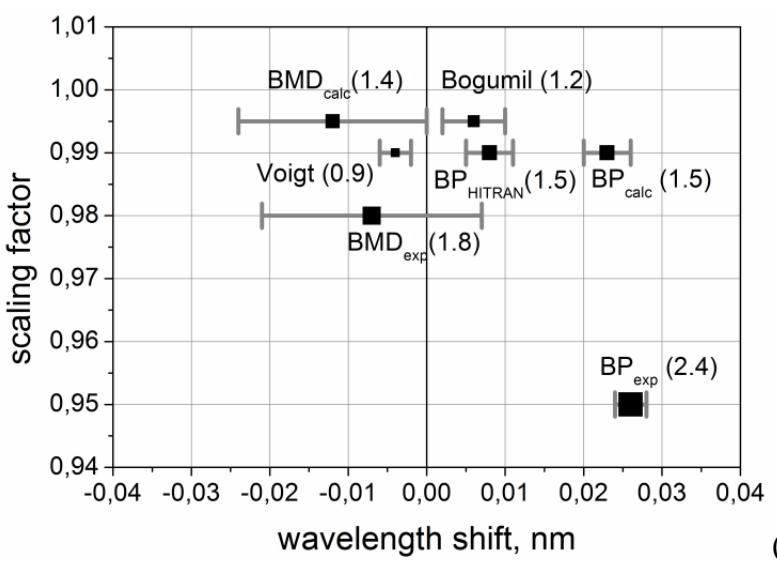

(a)

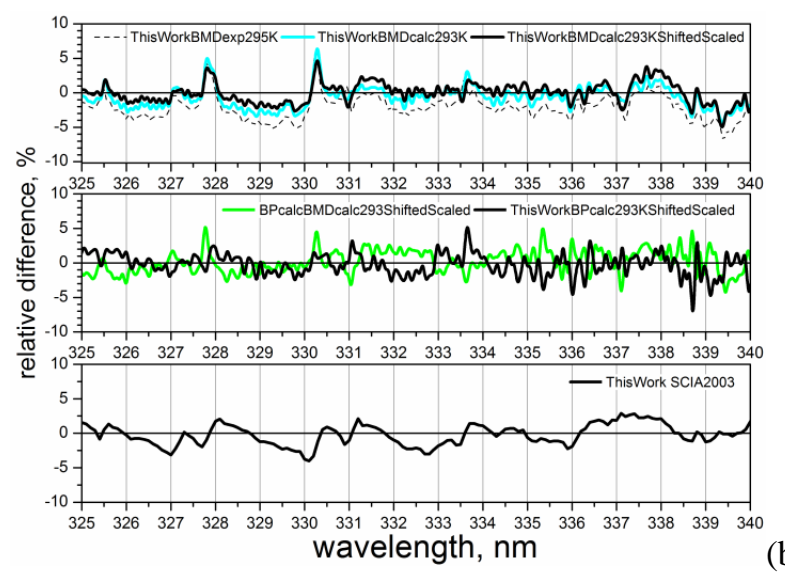

(b)

Fig. 5. Comparison of absorption cross-sections in Huggins band: (a) scaling factors and wavelength shifts between new data and other datasets (size of the symbols is proportional to the mean relative difference in percent given in brackets); (b) upper panel: relative difference between new data and BMD in percent. Dashed line - difference with $\mathrm{BMD}_{\text {exp }}$; light line - difference with $\mathrm{BMD}_{\text {calc }}$; dark line - difference with $\mathrm{BMD}_{\text {calc }}$ after wavelength shift and scaling. Middle panel: relative difference between $\mathrm{BP}_{\text {calc }}$ and $\mathrm{BMD}_{\text {calc }}$, and $\mathrm{BP}_{\text {calc }}$ and new data in percent after wavelength shift and scaling. Lower panel: relative difference between new data and Bogumil et al. (2003) in percent.

that of the new data is $1 \mathrm{~cm}^{-1}$. The shift between Bogumil et al. (2003) data and the new data is $0.006 \pm 0.004 \mathrm{~nm}$. We found that $\mathrm{BP}_{\text {calc }}$ and $\mathrm{BP}_{\text {HITRAN }}$ datasets agree with our new data within experimental uncertainty and show linear shifts of $+0.023 \pm 0.003$ and $+0.008 \pm 0.003 \mathrm{~nm}$, respectively; the shift of the $\mathrm{BP}_{\exp }$ is $+0.026 \pm 0.002 \mathrm{~nm}$, which means that original BP data must be shifted towards longer wavelengths to match our new measurements.

We also observe a non-linear wavelength calibration of the BMD dataset in the region 323-340 nm: different shifts were found for 323-330 and 332-340 nm regions. Assuming a mean linear shift, $\mathrm{BMD}_{\text {calc }}$ is shifted towards longer wavelengths relative to BP, Bogumil et al. (2003) and the 
Table 5. Absolute absorption cross-sections in minimum absorption region near $380 \mathrm{~nm}$ at $295 \pm 3 \mathrm{~K}, \mathrm{~cm}^{2}$ molecule ${ }^{-1} \times 10^{-23}$; typical FWHM, nm is given in brackets.

\begin{tabular}{rrrrrrr}
\hline $\begin{array}{r}\text { Vacuum } \\
\text { wavelength, nm }\end{array}$ & $\begin{array}{r}\text { This } \\
\text { work }\end{array}$ & $\begin{array}{r}\text { BMD } \\
(1998)\end{array}$ & $\begin{array}{r}\text { Burrows et } \\
\text { al. (1999) }\end{array}$ & $\begin{array}{r}\text { Bogumil et } \\
\text { al. (2003) }\end{array}$ & $\begin{array}{r}\text { Burkholder and } \\
\text { Talukdar (1994) }\end{array}$ & $\begin{array}{r}\text { Axson et } \\
\text { al. (2011) }\end{array}$ \\
\hline 365 & $4.9(0.02)$ & $4.74(0.02)$ & $6.26(0.17)$ & $5.11(0.21)$ & - & $3.68(0.27)$ \\
405 & $1.46(0.02)$ & $1.47(0.02)$ & $4.27(0.17)$ & $2.12(0.21)$ & $1.51(0.29)$ \\
455 & $20.6(0.02)$ & $20.4(0.02)$ & $22.9(0.29)$ & $21.4(0.52)$ & 18.2 & $18.8(0.5)$ \\
\hline
\end{tabular}

new datasets, while absolute values of cross-sections agree within experimental uncertainty (excluding $\mathrm{BP}_{\mathrm{exp}}$ ).

Possible biases between the original datasets in Fig. $5 \mathrm{~b}$ are masked by deviations of up to $5 \%$. Scaling and wavelength shifts reduce the relative difference to $0.5-2 \%$. The remaining differences can be attributed to noise in the measurements, non-linear wavelength differences, differences in the instrumental slit functions, and slight resolution mismatch between the considered datasets.

Apart from the analysis in the DOAS window, we compared our dataset with the published datasets at the selected single wavelengths used by different ozone-observing instruments in UV region. We used $\mathrm{BP}_{\text {calc }}$ and $\mathrm{BMD}_{\text {calc }}$ data calculated for $293 \mathrm{~K}$ using polynomial coefficients and Bogumil et al. (2003) data. Exhaustive comparison involves convolution of the datasets with instrument slit functions, which are not always well documented. For resolution-matching purposes, we convolved our new dataset, Bogumil et al. (2003), $\mathrm{BMD}_{\text {calc }}$ and $\mathrm{BP}_{\text {calc }}$ datasets to $1 \mathrm{~nm}$ using a rectangular slit function for comparing at SBUV, TOMS and Dobson wavelengths and to $0.4 \mathrm{~nm}$ for comparison with $\mathrm{OMI}$ and Brewer wavelengths. In the pair comparison (new-BMD $\mathrm{Bal}_{\text {calc }}$, new$\mathrm{BP}_{\text {calc }}$, and $\mathrm{BP}_{\text {calc }}-\mathrm{BMD}_{\text {calc }}$ ) we found that $\mathrm{BMD}, \mathrm{BP}$ and the new data agree within the accuracy of the measurements $(2 \%)$ for wavelengths below $320 \mathrm{~nm}$. In general, the new data are close to the BMD dataset, but slightly lower. At 320 $340 \mathrm{~nm}$, our new dataset is lower by 2-3 and 2-7\% compared to $\mathrm{BMD}$ and $\mathrm{BP}$, respectively.

\subsection{Chappuis and Wulf bands}

Satellite retrievals use the Chappuis and Wulf bands and adjoining Huggins and Chappuis bands for the ozone retrieval in limb and occultation experiments. In addition, accurate $\mathrm{O}_{3}$ absorption cross-sections in this spectral region are necessary for the retrieval of other trace gases, aerosols and clouds. The relative differences between the new absorption crosssections and published data are shown in Fig. 6 and discussed below.

\subsubsection{Minimum absorption region $350-450 \mathrm{~nm}$}

Various broadband datasets show large disagreement in the absorption minimum between the Huggins and Chappuis bands at $350-425 \mathrm{~nm}$ and especially near $380 \mathrm{~nm}$ as shown in Figs. 6 and 7a and in Table 5. Data given in Table 5 were

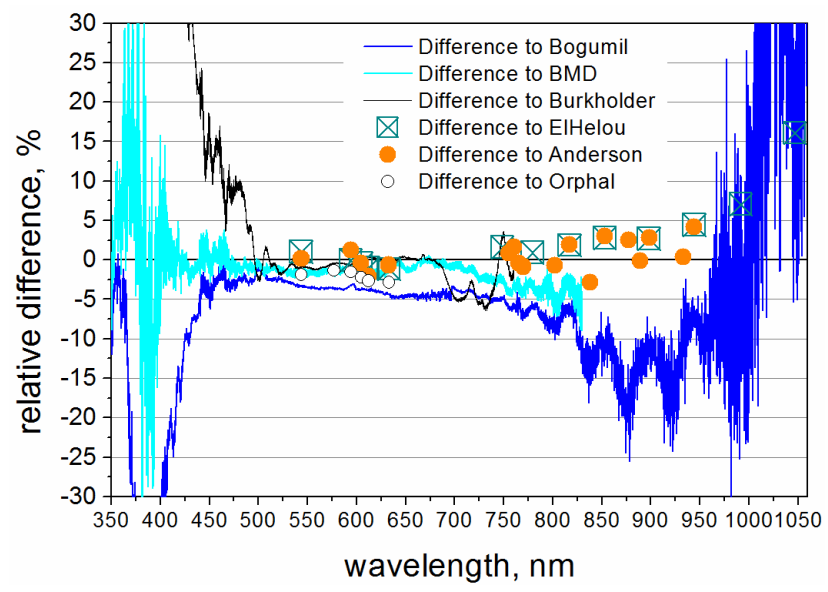

Fig. 6. Relative difference between the new cross-sections and published data in Chappuis and Wulf bands.

obtained at different spectral resolution as indicated by the numbers in brackets.

Additional data are available from measurements at single wavelengths recently performed by Axson et al. (2011) using incoherent broadband cavity-enhanced absorption spectroscopy. These relative measurements scale directly with the choice of reference cross-section value at $253.65 \mathrm{~nm}$. For absolute calibration, Axson et al. took the reference value reported by Orphal (2003) (Table 5). The reported accuracy of the Axson et al. (2011) cross-sections is $4-30 \%$, with the greatest uncertainty near the minimum absorption.

Our new absorption cross-section dataset agrees well with the BMD dataset and shows good agreement with data of Axson et al. (2011) within accuracy limits. There is a significant disagreement between the new dataset and Bogumil et al. (2003) data in the region of minimum absorption around $385 \mathrm{~nm}$ and in the IR region at $1020 \mathrm{~nm}$. In both regions, uncertainty of measurements is greater than $30 \%$ as a result of the very weak absorption measured.

\subsubsection{Visible region $450-700 \mathrm{~nm}$}

Several ozone absorption cross-section datasets are available in the visible region near the maximum of the Chappuis band (Fig. 7b). Absolute calibrated data of Anderson and Mauersberger (1992) were obtained using a tandem dual-beam spectrometer and pure ozone from the liquid nitrogen trap; 
Table 6. Absolute absorption cross-sections in the visible at $295 \pm 3 \mathrm{~K}, \mathrm{~cm}^{2}$ molecule ${ }^{-1} \times 10^{-21}$.

\begin{tabular}{rrrrrrrrr}
\hline $\begin{array}{r}\text { Wavelength, nm } \\
\text { vacuum (air) }\end{array}$ & $\begin{array}{r}\text { Orphal } \\
(2003)\end{array}$ & $\begin{array}{r}\text { This } \\
\text { work }\end{array}$ & $\begin{array}{r}\text { BMD } \\
(1998)\end{array}$ & $\begin{array}{r}\text { Burrows et } \\
\text { al. (1999a) }\end{array}$ & $\begin{array}{r}\text { Bogumil et } \\
\text { al. (2003) }\end{array}$ & $\begin{array}{r}\text { Anderson and } \\
\text { Mauersberger (1992) }\end{array}$ & $\begin{array}{r}\text { Burkholder and } \\
\text { Talukdar (1994) }\end{array}$ & $\begin{array}{r}\text { El Helou et } \\
\text { al. (2005) }\end{array}$ \\
\hline $543.67(543.52)$ & $3.14 \pm 1.3 \%$ & 3.08 & 3.12 & 3.17 & 3.16 & 3.075 & 3.11 & 3.051 \\
$577.12(576.96)$ & $4.77 \pm 0.8 \%$ & 4.70 & 4.77 & 4.83 & 4.84 & - & 4.72 & - \\
$594.26(594.10)$ & $4.70 \pm 1.2 \%$ & 4.63 & 4.68 & 4.76 & 4.74 & 5.569 & 4.66 & 4.631 \\
$604.78(604.61)$ & $5.22 \pm 1.0 \%$ & 5.10 & 5.18 & 5.24 & 5.25 & 4.125 & 5.12 & 5.125 \\
$612.14(611.97)$ & $4.66 \pm 0.7 \%$ & 4.54 & 4.63 & 4.69 & 4.68 & 3.633 & 4.52 & 4.586 \\
$632.99(632.82)$ & $3.46 \pm 1.2 \%$ & 3.36 & 3.39 & 3.51 & 3.48 & 3.37 & 3.401 \\
\hline
\end{tabular}

Table 7. Absolute absorption cross-sections in the NIR at $295 \pm 3 \mathrm{~K}, \mathrm{~cm}^{2}$ molecule ${ }^{-1} \times 10^{-22}$.

\begin{tabular}{rrrrrrrr}
\hline $\begin{array}{r}\text { Vacuum } \\
\text { wavelength, nm }\end{array}$ & $\begin{array}{r}\text { This } \\
\text { work }\end{array}$ & $\begin{array}{r}\text { BMD } \\
(1998)\end{array}$ & $\begin{array}{r}\text { Burrows et } \\
\text { al. (1999a) }\end{array}$ & $\begin{array}{r}\text { Bogumil et } \\
\text { al. (2003) }\end{array}$ & $\begin{array}{r}\text { Anderson et } \\
\text { al. (1993) }\end{array}$ & $\begin{array}{r}\text { Burkholder and } \\
\text { Talukdar (1994) }\end{array}$ & $\begin{array}{r}\text { El Helou et } \\
\text { al. (2005) }\end{array}$ \\
\hline 748.721 & 4.38 & 4.48 & 5.19 & 4.62 & - & 4.25 & 4.314 \\
755.21 & 3.22 & 3.36 & 4.04 & 3.47 & 3.194 & 3.26 & - \\
760.21 & 2.77 & 2.86 & 3.52 & 2.95 & 2.720 & 2.80 & - \\
765.21 & 2.53 & 2.62 & 3.33 & 2.72 & 2.539 & - & - \\
770.21 & 2.49 & 2.58 & 3.31 & 2.69 & 2.509 & - & 3.121 \\
779.416 & 3.15 & 3.25 & 3.99 & 3.37 & - & - & - \\
802.22 & 1.45 & 1.53 & - & 1.60 & 1.462 & - & 2.159 \\
817.224 & 2.20 & 2.26 & - & 2.34 & 2.157 & - & 1.420 \\
853.234 & 1.46 & - & - & 1.56 & 1.417 & - & - \\
877.24 & 0.377 & - & - & 0.422 & 0.368 & - & - \\
889.24 & 0.510 & - & - & 0.576 & 0.511 & - & - \\
898.247 & 0.638 & - & - & 0.714 & 0.620 & - & - \\
933.256 & 0.162 & - & - & 0.172 & 0.161 & - & - \\
944.259 & 0.424 & - & - & 0.458 & 0.407 & - & 0.406 \\
991.841 & 0.407 & - & - & 0.376 & - & - & 0.380 \\
1046.766 & 0.0773 & - & - & 0.0723 & - & & - \\
\hline
\end{tabular}

reported overall uncertainty of these measurements is below $1 \%$. Very recent absolute measurements performed by $\mathrm{El}$ Helou et al. (2005) using a FT spectrometer were calibrated using pure ozone as well, and have a reported uncertainty of $0.82 \%$.

The values of cross-sections at the selected wavelengths from the different datasets are listed in Table 6 (in some cases data were interpolated). The relative difference in percent between the new data and some published datasets is shown in Fig. 6.

In general, our new absorption cross-section measurements agree well with those obtained by Anderson and Mauersberger (1992) and El Helou et al. (2005) at the selected wavelengths (within about $1 \%$ or better). Our new data agree within $1 \%$ or better for the broad region $510-680 \mathrm{~nm}$ with those reported by Burkholder and Talukdar (1994), which were absolutely scaled using the data of Anderson and Mauersberger (1992). Agreement with BMD is also within the accuracy limits. Difference between new data and satellite datasets is about $2-3 \%$, which is almost within their experimental accuracy. We consider that the concatenation performed by Bogumil et al. (2003) might have had an impact on accuracy of the absolute calibration of this dataset in this spectral region.

\subsubsection{NIR region $700-1100 \mathrm{~nm}$}

Some of the datasets available in the NIR region are shown in Fig. 8. Data on selected wavelengths are compared in Table 7. Data of Anderson et al. (1993) obtained with a tandem dual-beam spectrometer were absolutely calibrated using the absolute cross-section reported by Anderson and Mauersberger (1992). In addition to the El Helou et al. (2005) data, there are measurements performed by Enami et al. (2004) at two single wavelengths at $760 \mathrm{~nm}$ using the cavity ring-down technique (Fig. 8a). The absorption crosssections of Enami et al. were calibrated using Hearn's value in the UV with the estimated total uncertainty of the $\mathrm{O}_{3}$ concentration of $\pm 1.5 \%$, and the typical overall uncertainty is about $\pm 2 \%$. However, accuracy of Hearn's value is not included in this uncertainty budget.

This region contains an absorption band of oxygen, which is visible, for example, in the Bogumil et al. (2003) dataset, measured in an oxygen-ozone mixture. No traces of oxygen spectrum are visible in the new dataset measured with pure ozone.

At wavelengths longer than $1050 \mathrm{~nm}$ ozone absorption decreases rapidly. Because of the experimental limitations, measured absorption in this region was weak and sensitive to 


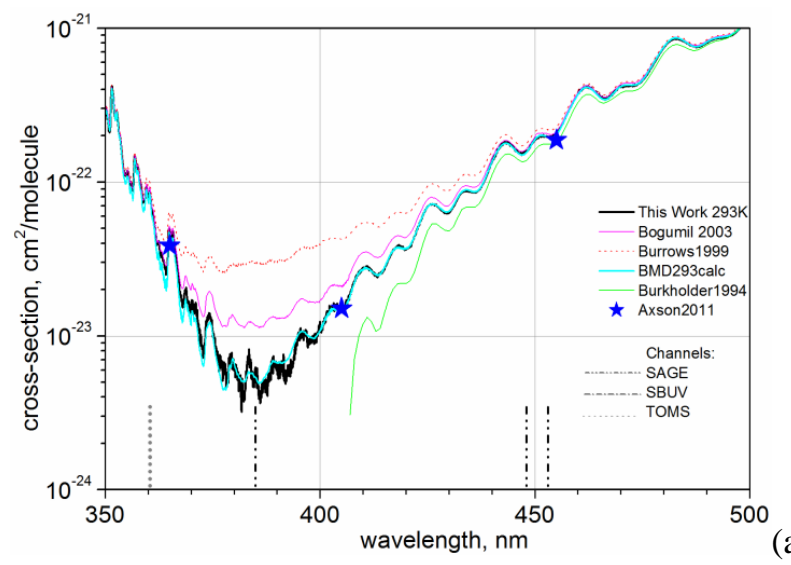

(a)

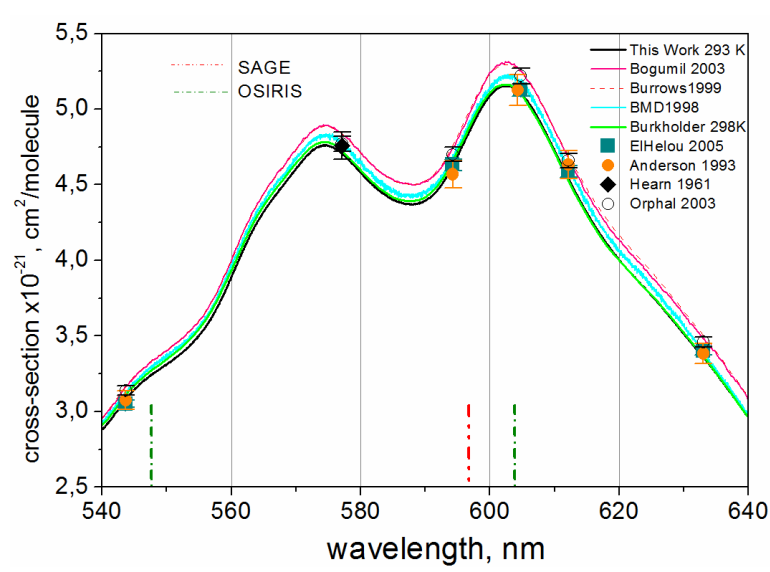

(b)

Fig. 7. Ozone absorption cross-sections in the Chappuis band: (a) near absorption minimum at $380 \mathrm{~nm}$, (b) at the maximum of the Chappuis band. Notations for datasets and spectral channels are the same as in Fig. 3; green solid line - Burkholder and Talukdar (1994).

the baseline stability. The uncertainty of our measurements around $1000 \mathrm{~nm}$ is about $30 \%$ or more. Only a few studies on $\mathrm{O}_{3}$ absorption cross-sections are available in this region. Results from Anderson et al. (1993) and El Helou et al. (2005) show agreement with the new dataset within $5 \%$ at wavelengths below $1000 \mathrm{~nm}$ and up to $20 \%$ around $1040 \mathrm{~nm}$ (Figs. 6 and 8b). Compared with Bogumil et al. (2003), our new dataset better resolves the rotational structure of the Wulf band. In general, the new dataset in the "valleys" near $970 \mathrm{~nm}$ and 1010-1040 nm are lower than the Bogumil et al. (2003) dataset, partly because of the different spectral resolution. Further measurements in this region are of high interest and promising both for $\mathrm{O}_{3}$ rotational spectra modelling and for use in satellite missions, for example for SAGE II and SAGE III (SAGE III ATBD Team, 2002).

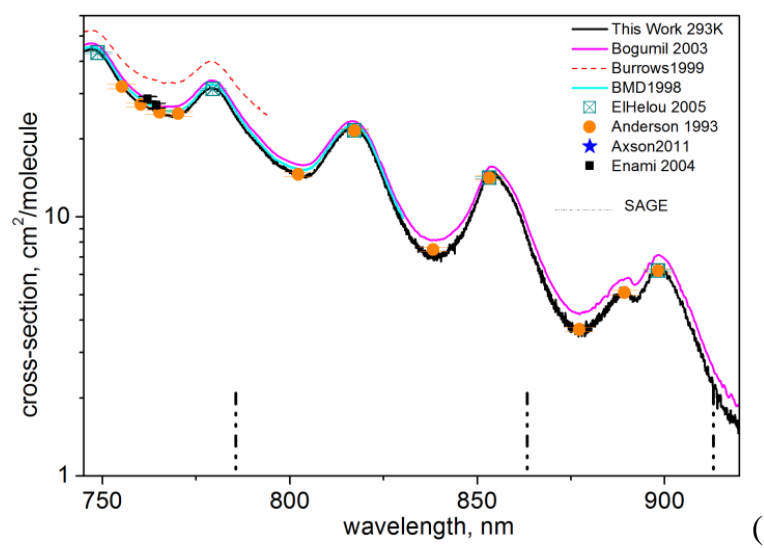

(a)

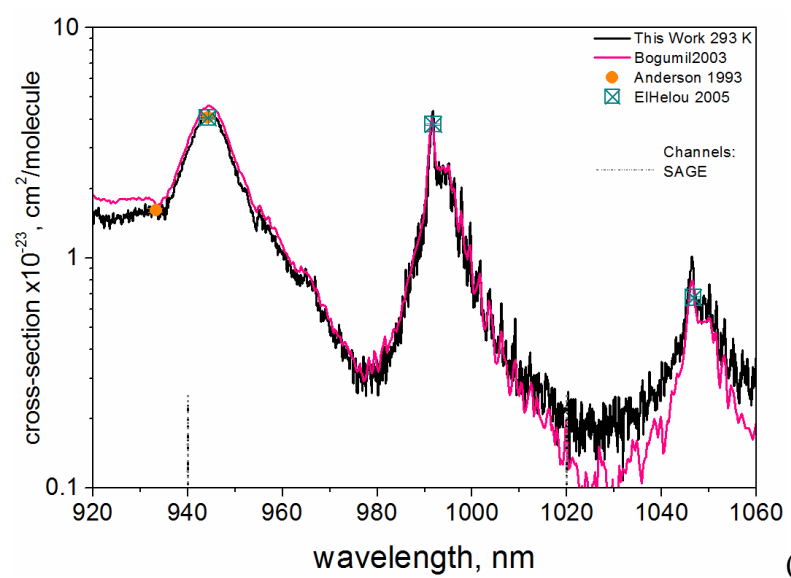

(b)

Fig. 8. Ozone absorption cross-section datasets in the Wulf band: (a) $750-900 \mathrm{~nm}$, (b) $920-1060 \mathrm{~nm}$. Notations for datasets and spectral channels are the same as in Fig. 3.

\section{Conclusions}

The experimental setups with two types of spectrometers (echelle and FTS) made it possible to obtain new broadband ozone absorption cross-sections covering the spectral region from the UV to the NIR, which contains spectral channels of numerous remote sensing instruments. A spectral resolution of at least one order of magnitude better than that of most remote sensing instruments was achieved. Absolute crosssections were measured using pure ozone in the absorption cell. Special attention was paid to ozone decay before and during the absorption measurements for which corrections were introduced.

Typically, relative datasets are scaled using single reference values in the UV region, for example, at $253 \mathrm{~nm}(\mathrm{Hg}$ emission line). In our work, absolute cross-sections were obtained for broad regions in the UV and visible parts of spectra in the Huggins and Chappuis bands. Relative measurements in the Hartley band, in the absorption minimum region between Huggins and Chappuis bands, and in the Wulf band were concatenated by scaling overlap regions to the absolute cross-sections. Thus, we could avoid uncertainty 
accumulation due to consecutive concatenations across a large spectral range up to the near IR.

From our experience with this work and by evaluating the uncertainty budgets of similar measurements reported in the literature, we conclude that $2-3 \%$ accuracy is the best that can be achieved in broadband cross-section measurements including ours so far. Single-wavelength measurements with higher accuracy can be of great help for improving absolute calibration. However, such measurements must be performed at several temperatures and at different wavelengths across the entire spectral range for reliable independent calibration of concatenated spectra.

Our new ozone cross-sections at room temperature are very close to the high-resolution BMD dataset; the agreement further improves if compared with BMD cross-sections interpolated to $293 \mathrm{~K}$ using the quadratic temperature dependence. Compared to the low-resolution satellite flight model data, the new data are systematically lower. However, all considered datasets agree within the reported experimental error bars for almost the entire spectral region when using conventional methods for data comparison. Part of the disagreement between datasets can be a result of the spectral resolution mismatch (particularly in the Huggins band), wavelength calibration errors, and temperature dependence as discussed above. Reported uncertainties should not be a crucial factor in the choice of cross-section data for remote sensing applications. Such a choice should be rather based on tests of the data in retrievals.

The second part of this study (Serdyuchenko et al., 2014) is devoted to the temperature effect in the new data. The new $\mathrm{O}_{3}$ absorption cross-section dataset combined with supporting technical documentation is made available from the website of the molecular spectroscopy laboratory of the Institute of the Environmental Physics, University of Bremen, Germany (http://www.iup.uni-bremen.de/gruppen/ molspec/databases/index.html).

Acknowledgements. The research has been carried out within the framework of a long-term research project at the Institute of Environmental Physics devoted to improving absorption cross-sections and line parameter datasets for atmospheric and planetary remote sensing and to studies of molecular physics. The above study has been supported in part by the European Space Agency (HARMONICS project), the State of Bremen, University of Bremen, and the German Aerospace Agency (DLR).

Edited by: P. Stammes

\section{References}

Anderson, S. M. and Mauersberger, K.: Laser measurements of ozone absorption cross-sections in the Chappuis band, Geophys. Res. Lett., 19, 933-936, 1992.

Anderson, S. M., Hupalo, P., and Mauersberger, K.: Ozone absorption cross-section measurements in the Wulf bands, Geophys. Res. Lett., 20, 1579-1582, 1993.

Axson, J. L., Washenfelder, R. A., Kahan, T. F., Young, C. J., Vaida, V., and Brown, S. S.: Absolute ozone absorption cross section in the Huggins Chappuis minimum (350-470 nm) at 296 K, Atmos. Chem. Phys., 11, 11581-11590, doi:10.5194/acp-1111581-2011, 2011.

Banichevich, A., Peyerimhoff, S. D., and Grein, F.: Potential energy surfaces of ozone in its ground state and in the lowest-lying eight excited states, Chem. Phys., 178, 155-188, 1993.

Bass, A. M. and Paur, R. J.: The Ultraviolet Cross-Sections of Ozone: I. The Measurements, in: Zerefos, C. S. and Ghazi, A., Atmospheric Ozone; Proc. Quadrennial Ozone Symposium, Halkidiki, Greece, 1984, Dordrecht, Reidel, D., 606-610, 1985.

Bhartia, P. K., McPeters, R. D., Flynn, L. E., Taylor, S., Kramarova, N. A., Frith, S., Fisher, B., and DeLand, M.: Solar Backscatter UV (SBUV) total ozone and profile algorithm, Atmos. Meas. Tech., 6, 2533-2548, doi:10.5194/amt-6-2533-2013, 2013.

Bogumil, K., Orphal, J., Homann, T., Voigt, S., Spietz, P., Fleischmann, O. C., Vogel, A., Hartmann, M., Bovensmann, H., Frerick, J., and Burrows, J. P.: Measurements of molecular absorption spectra with the SCIAMACHY pre-flight model: instrument characterization and reference data for atmospheric remotesensing in the $230-2380 \mathrm{~nm}$ region, J. Photoch. Photobiol. A., 157, 157-167, 2003.

Bovensmann, H., Burrows, J. P., Buchwitz, M., Frerick, J., Noel, S., Rozanov, V. V., Chance, K. V., and Goede, A. P. H.: SCIAMACHY: Mission Objectives and Measurement Modes, J. Atmos. Sci., 56, 127-150, 1999.

Brion, J., Chakir, A., Daumont, D., Malicet, J., and Parisse, C.: High-resolution laboratory absorption cross section of $\mathrm{O}_{3}$. Temperature effect, Chem. Phys. Lett., 213, 610-612, 1993.

Brion, J., Chakir, A., Charbonnier, J., Daumont, D., Parisse, C., and Malicet, J.: Absorption spectra measurements for the ozone molecule in the 350-830 nm region, J. Atmos. Chem., 30, 291299, 1998.

Burkholder, J. B. and Talukdar, R. K.: Temperature dependence of the ozone absorption spectrum over the wavelength range 410760 nm, Geophys. Res. Lett., 21, 581-584, 1994.

Burrows, J. P., Richter, A., Dehn, A., Deters, B., Himmelmann, S., Voigt, S., and Orphal, J.: Atmospheric remote-sensing reference data from GOME. 2. Temperature-dependent absorption cross sections of O3 in the 231-794 nm range, J. Quant. Spectrosc. Ra., 61, 509-517, 1999a.

Burrows, J. P., Weber, M., Buchwitz, M., Rozanov, V. V., LadstätterWeißenmayer, A., Richter, A., DeBeek, R., Hoogen, R., Bramstedt, K., and Eichmann, K. U.: The Global Ozone Monitoring Experiment (GOME): Mission Concept and First Scientific Results, J. Atmos. Sci., 56, 151-174, 1999b.

Chehade, W., Gür, B., Spietz, P., Gorshelev, V., Serdyuchenko, A., Burrows, J. P., and Weber, M.: Temperature dependent ozone cross-sections spectra measured with the GOME-2 FM3 spectrometer and first application in satellite retrievals. Atmos. Meas. Tech., 6, 1623-1632, doi:10.5194/amt-6-1623-2013a. 
Chehade, W., Gorshelev, V., Serdyuchenko, A., Burrows, J. P., and Weber, M.: Revised temperature-dependent ozone absorption cross-section spectra (Bogumil et al.) measured with the SCIAMACHY satellite spectrometer, Atmos. Meas. Tech., 6, 30553065, doi:10.5194/amt-6-3055-2013, 2013b.

Daumont, D., Brion, J., Charbonnier, J., and Malicet, J.: Ozone UV spectroscopy I: Absorption cross-sections at room temperature, J. Atmos. Chem., 15, 145-155, 1992.

Edlen, B.: The refractive index of air, Metrologia, 2, 71-80, 1966.

El Helou, Z., Churassy, S., Wannous, G., Bacis, R., and Boursey, E.: Absolute cross sections of ozone at atmospheric temperatures for the Wulf and the Chappuis bands, J. Chem. Phys., 122, 244311, doi:10.1063/1.1937369, 2005.

Enami, S., Ueda, J., Nakano, Y., Hashimoto, S., and Kawasaki, M.: Temperature-dependent absorption cross sections of ozone in the Wulf-Chappuis band at 759-768 nm, J. Geophys. Res., 109, D05309, doi:10.1029/2003JD004097, 2004.

Grebenshchikov, S. Y., Zhu, H., Schinke, R., and Qu, Z. W.: New theoretical investigations of the photodissociation of ozone in the Hartley, Huggins, Chappuis, and Wulf bands, Phys. Chem. Chem. Phys., 9, 2044-2067, 2007.

Griggs, M.: Absorption Coefficients of Ozone in the Ultraviolet and Visible Regions, J. Chem. Phys., 49, 857-859, 1968.

Harris, N. R .P., Ancellet, A., Bishop, L., Hofmann, D. J., Kerr, J. B., McPeters, R. D., Prendez, M., Randel, W. J., Staehelin, J., and Subbaraya, B. H.: Trends in stratospheric and tropospheric ozone, J. Geophys. Res., 102, 1571-1588, 1997.

Hearn, A. G.: The absorption of ozone in the ultra-violet and visible regions of the spectrum, P. Phys. Soc., 78, 932-940, 1961.

Keller-Rudek, H. and Moortgat, G. K.: MPI-Mainz-UV-VIS Spectral Atlas of Gaseous Molecules, last update 2013, available at: www.atmosphere.mpg.de/enid/Spectra/Presentation_4n3.html, last access: April 2013.

Komhyr, W. D. and Evans, R. D.: Operations handbook ozone observations with a Dobson spectrophotometer, Geneva: World Meteorological Organization Global Atmosphere Watch, Wmo/Td-No. 1469, available at: http://www.wmo.int/pages/ prog/arep/gaw/documents/GAW183-Dobson-WEB.pdf (last access: April 2013), 2008.

Liu, X., Chance, K., Sioris, C. E., and Kurosu, T. P.: Impact of using different ozone cross sections on ozone profile retrievals from Global Ozone Monitoring Experiment (GOME) ultraviolet measurements, Atmos. Chem. Phys., 7, 3571-3578, doi:10.5194/acp7-3571-2007, 2007.

Malicet, J., Daumont, D., Charbonnier, J., Chakir, C., Parisse, A., and Brion, J.: Ozone UV Spectroscopy.II: Absorption cross sections and temperature dependence, J. Atmos. Chem., 21, 263273, 1995.

McCormick, M. P., Zawodny, J. M., Veiga, R. E., Larsen, J. C., and Wang, P. H.: An overview of SAGE I and SAGE II ozone measurements, Planet. Space Sci., 37, 1567-1586, 1989.

McPeters, R. D., Bhartia, P. K., Krueger, A. J., Herman, J. R., Wellemeyer, C. G., Seftor, C. J., Jaross, G., Torres, O., Moy, L., and Labow, G., Byerly, W., Taylor, S. L., Swissler, T., and Cebula, R. P.: Earth Probe Total Ozone Mapping Spectrometer (TOMS) Data Products User's Guide, National Aeronautics and Space Administration, Goddard Space Flight Center, available at: http://badc.nerc.ac.uk/data/toms/earthprobe_userguide. pdf (last access: April 2013), 1998.
Molina, L. T. and Molina, M. J.: Absolute absorption cross-sections of ozone in the 185-350 nm wavelength range, J. Geophys. Res., 91, 14501-14508, 1986.

NOAA: Solar Backscatter Ultraviolet Instrument (SBUV/2) Version 8 Ozone Retrieval Algorithm Theoretical Basis Document (V8 ATBD), available at: ftp://ftp.orbit.nesdis.noaa.gov/ pub/smcd/spb/ozone/docs/SBUV2_V8_ATBD_020207.pdf (last access: April 2013), 2007.

Orphal, J.: A critical review of the absorption cross-sections of $\mathrm{O}_{3}$ and $\mathrm{NO}_{2}$ in the ultraviolet and visible, J. Photoch. Photobiol. A, 157, 185-209, 2003.

Paur, R. J. and Bass, A. M.: The Ultraviolet Cross-Sections of Ozone: II. Results and temperature dependence, in: Atmospheric Ozone; Proc. Quadrennial Ozone Symposium, Halkidiki, Greece, 1984, edited by: Zerefos, C. S. and Ghazi, A., Dordrecht, Reidel, D., 611-615, 1985.

Petersen, M., Viallon, J., Moussay, P., and Wielgosz, R. I.: Relative measurements of ozone absorption cross-sections at three wavelengths in the Hartley band using a well-defined UV laser beam, J. Geophys. Res., 117, D05301, doi:10.1029/2011JD016374, 2012.

Rothman, L. S., Gordon, I. E., Barbe, A., Benner, C. D., Bernath, P. F., Birk, M., Boudon, V., Brown, L. R., Campargue, A., Champion, J.-P., Chance, K., Coudert, L. H., Dana, V., Devi, V. M., Fally, S., Flaud, J.-M., Gamache, R. R., Goldman, A., Jacquemart, D., Kleiner, I., Lacome, N., Lafferty, W. J., Mandin, J.Y., Massie, S. T., Mikhailenko, S. N., Miller, C. E., MoazzenAhmadi, N., Naumenko, O. V., Nikitin, A. V., Orphal, J., Perevalov, V. I., Perrin, A., Predoi-Crosss, A., Rinsland, C. P., Rotger, M., Šimečkova, M. , Smith, M. A. H., Sung, K., Tashkun, S. A., Tennyson, J., Toth, R. A., Vandaele, A. C., and Auwera Vander, J.: The HITRAN 2008 molecular spectroscopic database, J. Quant. Spectrosc. Ra., 110, 533-572, 2009.

SAGE III ATBD Team: SAGE III Algorithm Theoretical Basis Document (ATBD) Solar and Lunar Algorithm, LaRC 47500-109, available at: http://eospso.gsfc.nasa.gov/eos_homepage/ for_scientists/atbd/docs/SAGEIII/atbd-sage-solar-lunar.pdf (last access: April 2013), 2002.

Scarnato, B., Staehelin, J., Peter, T., Groebner, J., and Stuebi, R.: Temperature and slant path effects in Dobson and Brewer total ozone measurements, J. Geophys. Res., 114, D24303, doi:10.1029/2009JD012349, 2009.

Schinke, R. and McBane, G. C.: Photodissociation of ozone in the Hartley band: Potential energy surfaces, nonadiabatic couplings, and singlet/triplet branching ratio, J. Chem. Phys., 132, 044305, doi:10.1063/1.3299249, 2010.

Serdyuchenko, A., Gorshelev, V., Weber, M., Chehade, W., and Burrows, J. P.: High spectral resolution ozone absorption crosssections - Part 2: Temperature dependence, Atmos. Meas. Tech., 7, 625-636, doi:10.5194/amt-7-625-2014, 2014.

OSIRIS Level 2 Daily Data Products: Users Guide, available at: http://odin-osiris.usask.ca/sites/default/files/media/pdf/ 12dataformat.pdf (last access: April 2013), 2012.

United Nations Environment Programme: Ozone Secretariat, available at: http://ozone.unep.org/new_site/en/index.php, last access: April 2013.

Veefkind, J. P. and de Haan, J. F.: DOAS Total $\mathrm{O}_{3}$ Algorithm, in: OMI Algorithm Theoretical Basis Document (ATBD), volume II: OMI Ozone Products, edited by: Bhartia, P. K., 33-52, 2002. 
Voigt, S., Orphal, J., Bogumil, K., and Burrows, J. P.: The temperature dependence $(203-293 \mathrm{~K})$ of the absorption cross sections of $\mathrm{O}_{3}$ in the $230-850 \mathrm{~nm}$ region measured by Fourier-Transform spectroscopy, J. Photoch. Photobiol. A., 143, 1-9, 2001.

Weber, M., Chehade, W., and Spietz, P.: Impact of ozone crosssection choice on WFDOAS total ozone retrieval applied to GOME, SCIAMACHY, and GOME2 (1995-present), Technical note Issue 2 Contribution to IGACO Activity: Absorption Cross-Sections for Ozone, available at: www.iup.uni-bremen.de/ UVSAT_material/manuscripts/weber_acso_201101.pdf (last access: April 2013), Bremen: Universität Bremen, 2011.
White, J. U.: Long optical paths of large aperture, J. Opt. Soc. Am., 32, 285-288, 1942.

Yoshino, K., Freeman, D. E., Esmond, G. R., and Parkinson, W. H.: Absolute absorption cross-sections measurements of ozone in the wavelength region $238-335 \mathrm{~nm}$ and the temperature dependence, Planet. Space Sci., 36, 395-398, 1988. 